Revista de la red interuniversitaria de estudios sobre las literaturas rioplatenses contemporáneas en Francia

$9 \mid 2013$

Homenaje a Ana María Barrenechea

\title{
Ana María Barrenechea y la crítica genética
}

\section{Élida Lois}

\section{OpenEdition}

\section{Journals}

Edición electrónica

URL: http://journals.openedition.org/lirico/1091

DOI: 10.4000/lirico.1091

ISSN: 2262-8339

Editor

Réseau interuniversitaire d'étude des littératures contemporaines du Río de la Plata

Referencia electrónica

Élida Lois, «Ana María Barrenechea y la crítica genética », Cuadernos LIRICO [En línea], 9 | 2013, Puesto en línea el 01 septiembre 2013, consultado el 21 abril 2019. URL : http://journals.openedition.org/ lirico/1091 ; DOl : 10.4000/lirico.1091

Este documento fue generado automáticamente el 21 abril 2019.

\section{(c) $(1) \Theta \Theta$}

Cuadernos LIRICO está distribuido bajo una Licencia Creative Commons Atribución-NoComercialSinDerivar 4.0 Internacional. 


\title{
Ana María Barrenechea y la crítica genética $^{1}$
}

\author{
Élida Lois
}

In memoriam Ana María Barrenechea, que como todos los grandes maestros sabía leer más allá de la letra escrita, enseñó a leer a otros y abrió nuevos rumbos.

1 Para quienes nos graduamos en la Facultad de Filosofía y Letras en el viejo edificio de Viamonte 430, Anita Barrenechea forma parte de un ubi sunt. En ese ubi sunt ella sigue correteando por la tarima del aula magna debajo del retrato de un Echeverría estilizado por Charton de Treville, y todavía la oímos cada vez que releemos « Piedra negra sobre una piedra blanca », « Entrada a la madera », « Funes el memorioso », etc., etc., porque esa voz no se limitaba a dictar una materia llamada «Introducción a la literatura »: nos franqueaba la entrada a un mundo mágico.

2 Allá por los ‘60 nos introdujo en un universo teórico que en el campo lingüístico-literario hizo el recorrido que fue desde la estilística y el estructuralismo hasta los albores del análisis del discurso, el generativismo y la sociolingüística, y cuando regresó a esta Facultad en 1984, en plena fructificación de un cambio de paradigmas, acababa de publicar Cuaderno de bitácora de Rayuela de Julio Cortázar (Barrenechea 1983), el análisis que marcó la entrada de la crítica genética en lengua española. No me refiero a la mirada geneticista, que tenía ya una prehistoria y hasta inicios académicos en nuestro país, sino a un marco teórico-metodológico específico que sólo puede interpretarse en un punto preciso de la historia intelectual.

3 A fines de la década del '60, un equipo del CNRS dirigido por Louis Hay comenzó a examinar un fondo de reciente adquisición en la Biblioteca Nacional de París: los manuscritos de Heinrich Heine. No es casual que las investigaciones de un grupo de germanistas dieran origen a la crítica genética, ya que en Alemania había comenzado a consolidarse desde fines del siglo XIX una tradición editorial de manuscritos modernos que advertía implícitamente sobre la necesidad de diferenciar la tarea de analizar posttextos del abordaje de pre-textos. Las ediciones críticas de textos modernos ya no se 
enfrentaban con copias sucesivas - que atravesaban geografías y épocas diversas - para poder construir sobre la base de su examen riguroso un original irremisiblemente perdido; el investigador se enfrentaba ahora con objetos de estudio de distinta naturaleza : manuscritos de trabajo escritural autógrafos y textos sucesivos con variantes en ediciones supervisadas por el propio autor.

Casi todos sus miembros eran normaliens, egresados de l'École Normale Supérieure, una institución que desde el apogeo del existencialismo hasta la apoteosis del postestructuralismo -justamente en esa transición de los '60 a los '70-, podía soñarse en la época en que París fue consagrada como la capital cultural del Mundo, e imagino que toparse con el proceso escritural de la Lutetia de Heine bien podría haberlos convencido de esa postulación. En el primer número de Scolies. Cahiers de Recherches de l'École Normale Supérieure, que comenzó a publicarse en 1971, mientras Pierre Bourdieu daba a conocer "Champ du pouvoir, champ intellectuel et habitus de classe », la pieza inaugural de una nueva etapa teórica en el campo de la sociología de la cultura, en «Critique, textes et manuscrits ", Louis Hay deslindaba ya un nuevo objeto de análisis pero se consagraba a una de las operatorias predilectas del estructuralismo : la taxonomía. Pero esta asincronía productiva se debía, sin duda, a que estos investigadores tenían que desprenderse no sólo del corset del estructuralismo sino de las arraigadas supersticiones acerca de la " edición crítica " instituidas por la Filología tradicional, un constructo tan arraigado que impulsaba a trasladar automáticamente a los manuscritos de autor (los manuscritos definidos como "lugares de trabajo escritural») las metodologías generadas para dar cuenta de objetos de estudio diferentes. Por eso, la teoría de la edición seguía hablando de «fijar el texto» cuando la sociolingüística ya había demostrado que el lenguaje es « variación ».

5 En 1974, Louis Hay reunió en una misma estructura académica a los grupos de investigadores de diversos corpora de pre-textos autorales (fondos Heine, Proust, Zola, Aragon, Flaubert, Valéry, Nerval, Joyce, Sartre, etc.) ; y en 1982, ese Centro se transformó en un laboratorio del CNRS, rebautizado como Institut de Textes et Manuscrits Modernes (ITEM). Y sobre la base de esos fluidos contactos con manuscritos de autor se consolidó la comprensión de que el concepto de pre-texto podía erigirse en la categoría descriptiva fundadora de una nueva disciplina : la « crítica genética ». Será, justamente, el enfoque de la escritura como producción de inscripciones materiales y como objetivación de procesos creativos lo que permitirá a esos investigadores acotar una zona privativa en el interior del campo académico.

6 Si bien el concepto de avant-texte y el empleo de una nueva metodología en el estudio de la génesis de un poema de Milosz puede datarse en 1972, su creador, el psicoanalista y crítico literario Jean Bellemin-Noël, habría de encauzar su investigación teorizando acerca de un enfoque psicoanalítico de la literatura que llamaría textanalyse (BelleminNoel 1972) ; por otra parte, sólo posteriormente se lo definiría con más rigor como el conjunto de todos los testimonios genéticos escritos de una obra o de un proyecto de escritura conservados, organizados en función de la cronología de etapas sucesivas. Además, aunque ya Roland Barthes había distinguido entre « escritura » y «texto » - y Julia Kristeva, entre géno-texte y phéno-texte-, fueron las investigaciones de los miembros del ITEM las que terminarían por desplazar el estatuto científico del texto para cedérselo a los manuscritos -definidos como «los papeles privados» del escritor - y al proceso genético de su constitución; por eso las primeras investigaciones focalizarían su trabajo en una « poética de la escritura » por oposición a una « poética del texto ». 
7 De todas maneras, fue solamente después de la publicación de dos compilaciones de aportes del grupo (una de 1979, y otra de 1980) ${ }^{2}$, que empezó a advertirse una nueva mirada sobre el trabajo escritural : ya se hablaba de una " crítica genética »; sin embargo, las principales elaboraciones teóricas acabadas de una auténtica « crítica genética » no se conocieron hasta 1984 (Hay 1984) y no alcanzaron su formulación más precisa y rigurosa hasta la década de los $90 .^{3}$ Sólo entonces se precisará con claridad la caracterización de la escritura en términos de tensión y recursividad, es decir, de avances atravesados por fuerzas que obligan a retroceder y recomenzar porque escribir es reescribir (así como pensar es repensar), como ya lo habían intuido Paul Valéry y Jorge Luis Borges, quien lo expresó así: "no puede haber sino borradores, el concepto de texto definitivo no corresponde sino a la religión o al cansancio » (Borges 1974 [1932]).

Por eso quiero recalcar que, anticipándose a esas elaboraciones teóricas ulteriores, y cuando sólo habían circulado entre nosotros el trabajo de Bellemin-Noël citado y esas dos recopilaciones de artículos monográficos que mostraban una elaboración teórica en gestación, Ana María Barrenechea supo leer allí más de lo que se decía. Cuando ella publicó, en 1983, Cuaderno de bitácora, todavía prevalecía en quienes manejaban el concepto de " pre-texto » la consideración de un complemento de la noción de « texto », de un camino para llegar a él. En ese contexto crítico, el análisis de un embrión textual de Rayuela aparece como una de las primeras muestras de editar génesis y de enseñar a leer génesis.

Siguiendo las rutas fluctuantes de la producción literaria a partir de papeles de trabajo escritural, Barrenechea llega inevitablemente a la noción de «texto» como " eventualidad", en otras palabras, a un cuestionamiento del concepto de texto que hasta entonces se había venido manejando. La huidiza direccionalidad de la escritura impide interpretar sus pasos en términos de reglas que, obedeciendo las pautas de un " modelo", desemboquen en un final previsible. En cambio, sí es posible hablar de un conjunto indeterminado de estrategias variables para cada situación. Las estrategias tienen una orientación, pero no pueden interpretarse en términos ortodoxamente teleológicos porque pueden no estar conscientemente dirigidas hacia un fin y no están necesariamente determinadas por él. Ahora bien, es cierto que aun cuando el objetivo no esté nítidamente recortado, la marcha de la escritura dibuja un recorrido hacia alguna parte : la textualización está dotada de una suerte de direccionalidad, pero en el camino puede detenerse, vacilar, cambiar de rumbo, diversificarse, y hasta explotar : se trata de una direccionalidad « virtual ». Así, de ese análisis de manuscritos cortazarianos surge ese concepto de «virtualidad textual » que Louis Hay condensaría en una famosa boutade («Le texte n'existe pas ») (Hay 1985) y que, en otro campo, la informática se ha ocupado de corroborar a partir de sus procesamientos y manipulaciones de datos.

Pero además de hacer aportes metodológicos (ya que caracteriza subtipos de pre-textos que imponen peculiares abordajes analíticos), y además de analizar en la dinámica creativa una poética de la escritura cortazariana, Barrenechea advierte la significación de una nueva corriente en los estudios filológicos y teoriza sobre su irrupción. La ubica en el marco general de un movimiento científico que cambia los paradigmas : la psicología con su avance en el estudio de los procesos cognitivos, el psicoanálisis con sus nociones de pulsión, desplazamiento, condensación y sus modelos que cuestionan la unidad del Yo; la lingüística en sus orientaciones generativistas y su empleo de operaciones de transformación; la sociolingüística, que comprende la naturaleza del cambio lingüístico cuando descubre que la variación es una condición sine qua non del funcionamiento del lenguaje ; las teorías del discurso que incorporan la pragmática y piensan la interacción 
verbal como un conjunto de estrategias en proceso; las teorías marxistas sobre la producción, aplicadas con mayor o menor acierto a la literatura ; el deconstruccionismo de Derrida, que desestabilizando formulaciones que se imaginaban inmutables hace hallazgos luminosos ; y una ciencia literaria que estimula una crítica de la escritura y de la lectura. En ese contexto, durante la segunda mitad del siglo XX una renovada concepción del trabajo escritural da lugar a la aparición de una auténtica «crítica genética ", que intenta desarrollar una conciencia teórica y una operatoria metodológica que reencauza de otro modo las prácticas filológicas existentes (Barrenechea 1983: 13-19).

11 Para entender esa capacidad para leer lo que aún no habían escrito los creadores de la corriente que habría de autodefinirse como una "nueva disciplina " (Lebrave 1992), es insoslayable calibrar la agudeza de Barrenechea para leer textos y procesos de escritura sin dejar de percibir paralelamente la evolución del pensamiento crítico, pero tampoco podemos dejar de considerar -y menos en este ámbito - el marco intelectual en el que ella se formó. Trabajó bajo la dirección de Pedro Henríquez Ureña y Amado Alonso (y subrayo que fue ella misma quien me señaló que había que nombrar en ese orden a quienes ya habían sido sus profesores en el Instituto Nacional del Profesorado, pero que se convirtieron en sus " maestros " y la guiaron para transformarse prontamente en una « investigadora formada » en el Instituto de Filología de la Facultad de Filosofía y Letras). Y así como los teóricos geneticistas de la Escuela del ITEM definieron una nueva línea crítica cuando lograron desplazarse desde el objetivismo abstracto de las sistematizaciones estructuralistas hacia modelos más abarcadores y flexibles, Amado Alonso -formado en la escuela filológica de Menéndez Pidal, que había combinado el rigor descriptivo de los neogramáticos con la consideración del lenguaje como un fenómeno inseparable de los procesos sociales y culturales - supo incorporar a esa formación básica de manera original tanto concepciones idealistas como estructuralistas. Henríquez Ureña, a su vez, tenía no sólo la capacidad de interpretar procesos culturales : tenía la virtud de generarlos. Anita supo hacer rendir al máximo ese sustrato que la capacitó para percibir con facilidad el sentido de fenómenos culturales de naturaleza dinámica, y en esta línea, las investigaciones sobre génesis escritural emergieron dentro de su producción (ya por entonces celebrada internacionalmente) como la culminación de una línea crítica.

12 Al año siguiente de la publicación del Cuaderno de bitácora, ella volvió a hacerse cargo de la dirección del Instituto de Filología e impulsó emprendimientos que contribuyeron a difundir esa línea de investigaciones. Se trata de estudios lentos y trabajosos, que nunca atrajeron en nuestro país a legiones de practicantes, y es más, podría decirse que sólo treinta años después empiezan a verse ahora equipos de investigación radicados en varias universidades nacionales que trabajan en esta área. Pero todos esos grupos reconocen su origen en ese libro y en las primeras actividades de difusión impulsadas por Anita.

13 Aquí dirigió varias tesis doctorales encuadradas en esta corriente, entre ellas la de María Inés Palleiro, una estudiosa de procesos de creación oral a quien ella señaló que el marco teórico-metodológico de la crítica genética era aplicable también a esos procesos creativos y que así se convirtió en una pionera en este tipo de estudios, y hoy dirige grupos de trabajo en esta área. En 1994, se consagró a la crítica genética un número de la revista Filología (Lois 1994), para el que fueron convocados tres teóricos destacados del ITEM para presentar artículos medulares (Louis Hay, Almuth Grésillon y Jean-Louis

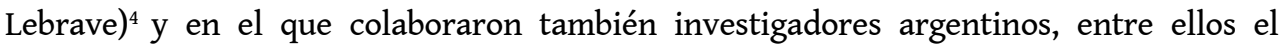
equipo del Instituto que colaboraba en estas actividades. Dos años después, secundada por 
el mismo equipo, Anita organizó un Seminario sobre "Introducción a la crítica genética ", en el que participaron como cursantes algunos de los principales investigadores que hoy, a su vez, dirigen proyectos dedicados al relevamiento de archivos de escritura, a su análisis y edición. Además, asociado a todas estas actividades, poco después se publicó en Argentina el primer manual de crítica genética escrito en español (Lois 2001).

Hay que consignar, también, que Anita dirigió entre 1985 y 2002 dos proyectos de investigación sucesivos («Edición del Epistolario inédito de Sarmiento » $\mathrm{y}$ « Archivos de la Memoria $\left.{ }^{6}\right)$, dos emprendimientos que conjugaron las teorías del archivo y el geneticismo textual con la marcha de la Historia, en los que se promovió la lectura de textos y pre-textos agotando todos sus sentidos. Desde esta óptica, no se concibe el examen y la interpretación de procesos de producción de sentido divorciados de la evolución de sus referentes externos, por eso se incorpora el análisis de una covariancia entre dinámica escritural y dinámica social. Entre otros seguidores de esta línea, se cuenta el "Programa de crítica genética » que hoy dirige Graciela Goldchluk en la Universidad de La Plata y el proyecto de «Edición del Archivo Documental de Juan Bautista Alberdi » en el que actualmente trabajo juntamente con Lucila Pagliai en la Universidad Nacional de San Martín. Y en esa herencia se inscribe, también, el seminario de "Genética textual y crítica genética » de la Maestría de Análisis del discurso de esta Facultad, que se dicta desde $1997 .^{7}$

15 También había sido prevista en la clase inaugural de Anita en su seminario de 1996 la expansión de las investigaciones geneticistas más allá de la literatura para encarar otros lenguajes artísticos (la escritura musical, la ejecución de obras plásticas y arquitectónicas, las representaciones escénicas, las realizaciones cinematográficas), y más allá de los procesos creativos para analizar la gestación del discurso científico. Actualmente, María Inés Palleiro ha emprendido una de esas líneas en el estudio de la génesis de danzas folklóricas, pero particularmente, todos los trabajos que se fueron enhebrando a partir del impulso inicial encontraron su mayor repercusión (dicho esto en términos del número de sus practicantes) en las escuelas de teatro universitarias. Fue pionera en el estudio de la génesis de puestas escénicas la Escuela de Teatro de la UNICEN, con sede en Tandil, que en 2009 coorganizó un congreso multitudinario sobre el tema realizado en la Universidad de Córdoba.

Pero resta mencionar otro dato importante para situar las peculiaridades de una práctica de la crítica genética en Latinoamérica porque se trata de un emprendimiento con el que Anita estuvo fuertemente vinculada : la aparición de la Colección Archivos, manifestación editorial de la Association Archives de la Littérature Latino-Américaine. Este proyecto surgió en un Centro de la Universidad de París X (posteriormente radicado en la Universidad de Poitiers y asociado al ITEM / CNRS), y se enmarcó en un Programa Internacional de la UNESCO : «Salvaguarda de la memoria escrita latinoamericana ». Ella -por ser entonces el único miembro argentino del Comité Científico Internacional de la Colección - fue convocada en 1984 por la Cancillería (juntamente con autoridades de nuestro país y con representantes de otros gobiernos latinoamericanos y de esa Asociación) para firmar el acuerdo de colaboración cuya expresión material está representada por más de 60 volúmenes en circulación (15 de los cuales son textos de autores argentinos y 11 de ellos publican ediciones crítico-genéticas). Es cierto que la Colección se había presentado orientada hacia la edición crítica de textos "canónicos » y el material pre-textual se exhibía como un camino orientado a establecer el mejor texto posible (que el Programa define como « el último aprobado por el autor ", propósito que puede ser objetado como 
objeto estético pero no como documento histórico) ; pero en los casos en que el material pre-textual es particularmente relevante, no caben dudas acerca de que se presenta una posibilidad de hacer leer génesis. Y es en este punto que el Programa Archivos se postula como un espacio de construcción para una crítica genética latinoamericana, y mientras Anita ocupó su Dirección, el Instituto de Filología de esta Facultad fue la Sede Académica del Programa para el Cono Sur. Actualmente, se han multiplicado sus sedes latinoamericanas, y en nuestro país existen varias subsedes académicas que desarrollan diferentes actividades vinculadas con emprendimientos del Centre de Recherches LatinoAméricaines del CNRS, que ha reiniciado la publicación de la Colección en una « Nueva Serie " $y$ en extensiones digitales.

Para concluir, un recuerdo reciente, que me retrotrae otra vez a mi ubi sunt. Al cabo de la presentación de un ensayo sobre Quevedo y Rabelais -corolario de un largo proceso escritural por donde también Anita entró, salió y dejó huellas - ${ }^{8}$, su autora, Susana Artal, pidió al público un minuto de silencio para dedicarlo a pensar en todo lo que Ana María Barrenechea significó para cada uno de nosotros. Muchos de los que nos concentramos en recordarla durante ese minuto de silencio nos plegamos hoy al «sonido». Por eso, no puedo evitar ahora seguir escuchando en su voz estos dos versos de Neruda que también resonaron en Viamonte 430: "y hagamos fuego, y silencio, y sonido, / y ardamos, y callemos, y campanas ».

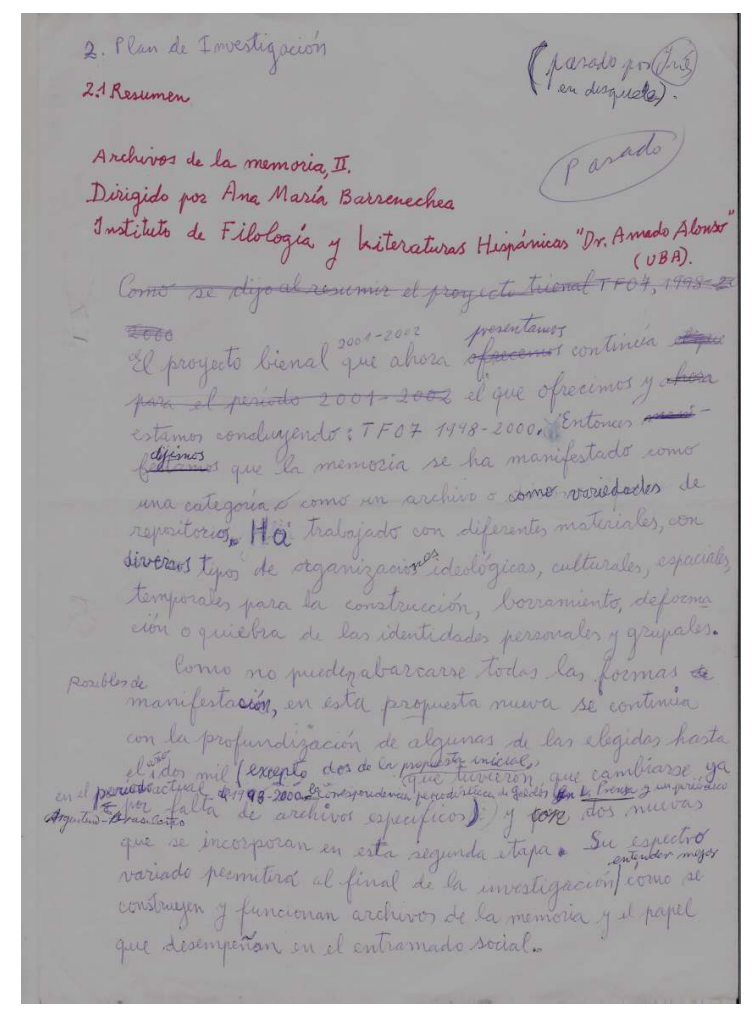

Borrador de Ana María Barrenechea (Proyecto "Archivos de la memoria") 


\section{BIBLIOGRAFÍA}

Barrenechea, Ana María. Cuaderno de bitácora de Rayuela de Julio Cortázar. Buenos Aires :

Sudamericana, 1983.

Barrenechea, Ana María y colaboradores. Sarmiento - Frías. Epistolario inédito. Edición crítica anotada. Buenos Aires : Facultad de Filosofía y Letras - UBA, 1997.

Barrenechea, Ana María (ed.). Archivos de la memoria. Rosario : Beatriz Viterbo, 2003.

Bellemin-Noël, Jean. Le texte et l'avant-texte. Les brouillons d'un poème de Milosz. Paris : Larousse, 1972.

Borges, Jorge Luis. «Las versiones homéricas ». En Obras completas, I. Buenos Aires : Emecé, 1974, pp. 239-243. [1 $1^{\mathrm{a}}$ ed. : Discusión. Buenos Aires : Manuel Gleizer, 1932.]

Contat, Michel et Daniel Ferrer (éds.). Pourquoi la critique génétique? Méthodes, théories. Paris : CNRS Éditions, 1998.

Debray Genette, Raymonde (éd.). Flaubert à l'œuvre. Paris : Flammarion, 1980.

Grésillon, Almuth. Eléments de critique génétique. Lire les manuscrits modernes. Paris : PUF, 1994.

Hay, Louis (éd.). Essais de critique génétique. Paris : Flammarion, 1979.

Hay, Louis. « Die dritte Dimension der Literatur ». Poetica [Amsterdam], 16, 3-4, 1984, pp. 307-323. [Traducción al francés : « Nouvelles notes de critique génétique : la troisième dimension de la littérature ». Texte [Toronto], 5-6, 1986, pp. 313-328.]

Hay, Louis. « Le texte n'existe pas ». Poétique, 62, 1985, pp. 147-158.

Hay, Louis. « L'écriture vive ». En Les manuscrits des écrivains (L. Hay, éd.), Paris : CNRS- Éditions Hachette, 1993, pp. 10-33.

Lebrave, Jean-Louis. « La critique génétique : une discipline nouvelle ou un avatar moderne de la philologie? ». Paris : Genesis, 1, 1992, pp. 33-72.

Lois, Élida (ed.). Filología [Buenos Aires], XXVII, 1-2, 1994. [Número monográfico : « Crítica genética ».]

Lois, Élida. Génesis de escritura y estudios culturales. Introducción a la crítica genética. Buenos Aires : Edicial, 2001.

\section{NOTAS}

1. Conferencia pronunciada en la Jornada de Homenaje a Ana María Barrenechea (Instituto de Filología de la Facultad de Filosofía y Letras de la Universidad de Buenos Aires, 10 de octubre de 2012). Se ha agregado un epígrafe y notas bibliográficas, además de la página manuscrita de Barrenechea (gentileza de Susana Artal).

2. Ver Hay 1979 et Debray Genette 1980.

3. En los trabajos de : Lebrave, Jean-Louis. «La critique génétique : une discipline nouvelle ou un avatar moderne de la philologie?». Paris: Genesis 1, 1992, p. 33-72 ; Hay, Louis. «L'écriture vive». En L. Hay (edit.). Les manuscrits des écrivains. Paris: CNRS- Éditions Hachette, 1993, 
p. 10-33 ; Grésillon, Almuth. Eléments de critique génétique. Lire les manuscrits modernes. Paris : PUF, 1994 ; Contat, Michel et Daniel Ferrer (eds.). Pourquoi la critique génétique? Méthodes, théories. Paris : CNRS Éditions, 1998.

4. Ver en Lois 1994 : Hay, Louis. «La escritura viva ». (5-23) ; Grésillon, Almuth. «Qué es la crítica genética ». (25-52) (traducciones de M. I. Palleiro) ; Lebrave, Jean-Louis. «La crítica genética : ¿una nueva disciplina o un avatar moderno de la filología? ». (53-73) (traducción de S. G. Artal).

5. Ver Barrenechea, Ana María y colaboradores 1997. Se trata de una edición crítica, pero a lo largo de un corpus que se extiende desde 1843 hasta 1878, puede advertirse un proceso de génesis del discurso epistolar.

6. Ver Barrenechea 2003. En una compilación de alcance más amplio, no está ausente la memoria de los procesos de engendramiento textual.

7. Estuvo a mi cargo desde 1997 hasta 2007 y hoy es dictado por Lucila Pagliai.

8. Artal Maillie, Susana G. Francisco de Quevedo y François Rabelais: Imágenes deshumanizantes y representación literaria del cuerpo. Pamplona, EUNSA, 2012.

\section{RESÚMENES}

El análisis geneticista irrumpe en la producción de Ana María Barrenechea como la culminación de una línea crítica. Consecuentemente, esta orientación domina la última etapa de su magisterio en la Facultad de Filosofía y Letras de la Universidad de Buenos Aires. Se hace aquí una sucinta revista de algunos hitos de ese magisterio y de sus últimos emprendimientos.

L'analyse génétique apparaît dans l'oeuvre d'Ana María Barrenechea à la manière du point culminant d'une ligne critique. Cette orientation domine ainsi la dernière période de son magistère dans la Faculté de Philosophie et Lettres de l'Université de Buenos Aires. L'article propose un succinct passage en revue de quelques jalons de ce magistère ainsi que de ses derniers projets.

The genetic analysis appears in the work of Ana María Barrenechea as the culminant point of her criticism. Consequently, this orientation prevails in the last period of her academic practice in the Faculty of Philosophy and Letters of the University of Buenos Aires. This article proposes a short review of some milestones of that practice and of her last projects.

\section{ÍNDICE}

Keywords: pre-text, rewriting, genetic edition, genetic reading, virtual texts

Palabras claves: pre-texto, reescritura, edición genetic, lectura genetic, virtualidad textual

Mots-clés: pré-texte, réécriture, édition génétique, lecture génétique, virtualité textuelle

\section{AUTOR}

ÉLIDA LOIS

CONICET-Universidad Nacional de San Martín 
elois@conicet.gov.ar 